\title{
Research into the Innovation and Entrepreneurship Practical Education about IT Specialty in Applied Undergraduate Colleges
}

\author{
Xie Nan * \\ College of Information Engineering and Art Design \\ Zhejiang University of Water Resources and Electric \\ Power \\ Hangzhou, China \\ 595075251@qq.com \\ * Corresponding Author \\ Wang Ying \\ College of Mechanical and Electrical Engineering \\ China Jiliang University \\ Hangzhou, China \\ sara.wy@163.com
}

\author{
Chen Weimin \\ College of Mechanical and Electrical Engineering \\ China Jiliang University \\ Hangzhou, China \\ c9419@sina.com
}

\begin{abstract}
Combined with the current innovation and entrepreneurship education theory research, classroom teaching, teacher innovation ideas, professional training, competition and other aspects of teaching experience, an innovative entrepreneurship education concept has been put into professional teaching channel, meanwhile, the corresponding education teaching system has been integrated into professional core curriculum. The students' value orientation, curriculum system and course teaching evaluation have been considered in the related teaching system analysis. As students' knowledge, skills and emotional integration of Education as the core, a practice platform has been proposed in IT specialty's students in applied undergraduate colleges based on the students' practical education of innovation and entrepreneurship. The incentive platform has been made up of five different subplatforms, and the platform has multi levels, stages, and gradually realizes innovating and practicing education, and trains students to take sustainable development path with high quality skilled personnel. The practical platform has good practice and practical.
\end{abstract}

Keywords- Applied Undergraduate Colleges; IT Speciality; Innovation and Entrepreneurship Education; Practice Platform

\section{INTRODUCTION}

The course of "innovation and entrepreneurship base" is gradually incorporated into the undergraduate course, and the innovation and entrepreneurship education becomes the focus of education research. Innovation and entrepreneurship education in the broad sense is the quality of education, in the narrow sense it is the skills training. While the application oriented undergraduate students of IT on innovation and entrepreneurship practice education pay more attention to the cultivation of students' entrepreneurial ideas and innovative thinking, not only imparting knowledge and skills, but also enhancing the level of professional skills and entrepreneurial awareness from various practical education process, and improving the professional quality and soft capacity of IT specialty.

At present, there are deviations in the implementation process of IT specialty innovation and entrepreneurship education and personnel training program. We must pay attention to strengthening the cultivation of students' pioneering consciousness, deepening the teaching system of entrepreneurship education, and creating a better practice education platform in order to seek more and more new ideas and solutions for the innovation and entrepreneurship education in our colleges and universities.

\section{INNOVATION AND ENTREPRENEURSHIP EDUCATION TEACHING SYSTEM ANALYSIS}

The higher education in our country should be carried out as a lifelong learning process, and the teaching system of innovation and entrepreneurship education should be gradually perfected, and the training program must be different levels and differences, and cannot be separated from the foundation of professional education [1-3, 10]. It will be used to construct a practical education system which is suitable for the application oriented undergraduate college IT. The following three parties are mainly been considered.

\section{A. Value Orientation}

From age, knowledge or government policies, IT students of application oriented undergraduate colleges are regarded as a rare advantage of college students' entrepreneurship and entrepreneurial mainstream. As 
Huang Boyun, the former president of Central South University saying, the innovation and entrepreneurship education is not only the reform of educational methods, but the orientation of educational functions, and is a value pursuit with comprehensive, structured education reform and education development. Such a scientific understanding needs our teachers put innovative and entrepreneurial ideas into the whole process of training and education, as shown in Fig. 1.

IT professional students want to start the system of professional skills training and education, will be innovative entrepreneurship education into professional teaching process, and the real purpose of education is to give students a good value orientation, from the entrepreneurial perspective on their SWOT analysis (that is, Strength advantages, Weakness analysis, Opportunity analysis and Threat analysis), to seize the opportunity to clear their own development direction, and find out the main actual situation of the gap and shortage, to build a business concept, and ultimately realize their own value, or to survive, or to make their own social recognition and contribute to social development. Students in professional education, innovation and entrepreneurship practice education and some skills training in SWOT analysis, in particular SW (strengths and weaknesses) and OT (opportunities and threats) analysis of the two categories, and then stimulate the potential of students innovation and entrepreneurship, from the macro and micro perspective of the internal environment and competitive conditions of the situation analysis, establish a correct business sense and value orientation[2-4,7].

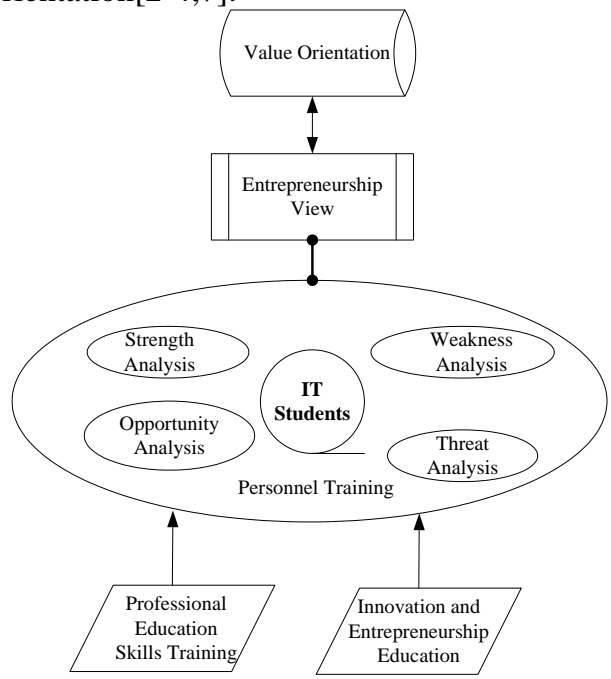

Figure 1. the Value Orientation of Practical Education

\section{B. Curriculum System}

The course system construction of the innovation and entrepreneurship education of IT major students in Applied Undergraduate Colleges and universities can be started from the three aspects: curriculum module construction, curriculum teaching and teaching evaluation.

\section{1) Course Module Construction}

Course construction is the key and the core of innovation and entrepreneurship education system, the effect of curriculum construction directly determines the training plan and goal of professional talents, and the living space and social value of innovation and entrepreneurship education to the vertical development. The challenge to entrepreneurship education is not how to expand the scope of this field, but how to promote the development of current curriculum, to improve the curriculum quality. Therefore, the most important is to set up the target of IT, and to determine the overall educational objectives of the whole talents training course system in the applied undergraduate colleges. And according to the reality of the social reality, the students themselves are different conditions of the "differentiation" curriculum teaching, so that students "do high school, learn to do", and constantly sum up the curriculum, the accumulation of professional skills and a certain professional quality.

\section{2) Curriculum Teaching}

In innovation and entrepreneurship education curriculum system construction process, must break the traditional teaching idea, the teacher is dominant, the teaching mode is fixed, the curriculum teaching emphasis on systematic and complete knowledge teaching and neglect of knowledge, the students lack the ability to think independently, especially in the classroom practice, but also not to mention outside and out of school practice, theory and practice. For example, in the teaching objectives, the teaching task is to complete the teaching task for the purpose, so that students' comprehensive ability, in the teaching process to teachers, to book knowledge, teaching term characters, students mostly quiet listening, recording, the classroom atmosphere is depressed, boring, teaching method is simple, and the students lack of awareness, the teaching effect is poor. For the application oriented undergraduate students in IT, innovation and entrepreneurship education curriculum teaching methods should be more flexible and diversified, such as task driven method, project teaching method, based on CDIO (that is, (Conceive), design (Design) and Operate (Implement)) teaching mode, curriculum reform and innovation and entrepreneurship practice education integration, complement each other $[8,10]$. IT professional courses teaching and innovation and entrepreneurship practice education must be connected to each other, and always will be "within the course of teaching activities," "extracurricular activities" and "outside school practice teaching activities" into one, forming an organic cycle process, as shown in Fig.2.

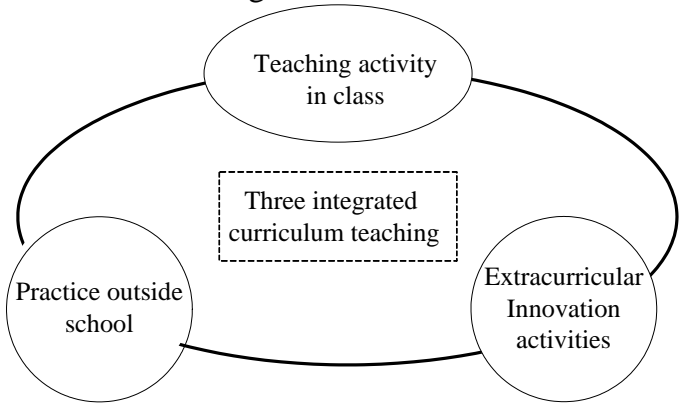

Figure 2. Curriculum three integrated teaching

Application oriented Undergraduate Colleges and universities in the course of IT teaching activities using a variety of teaching methods, such as task driving method, project case teaching, CDIO mode "teaching, learning, doing" integrated teaching, students and teachers for the double subject teaching subject interaction, especially 
CDIO mode teaching more attention to practical and innovative ability training, it will be the engineering basic knowledge, personal ability, interpersonal skills and engineering system capacity of four levels of teaching integration. Extracurricular innovation activity is the subject of the study of the subject of the study of the subject of the study of the subject of the research project or research and Entrepreneurship Program. The practical activity of the school is based on the professional needs of the task driven by the dual subject of innovative practice. The teaching practice of this kind of teaching is more attention to the teaching practice. The students can achieve "teaching, learning and doing" in the classroom, and the teacher's teaching activities are integrated, and the teaching activities are integrated.

\section{3) Course Teaching Evaluation}

IT professional and innovative entrepreneurship education curriculum module setting and teaching method can better meet the needs of professional construction, whether to achieve the goal of innovation and entrepreneurship education and practice, it is necessary to establish a curriculum evaluation criteria, on the one hand from the perspective of students in teaching assessment, curriculum testing and assessment, practical ability test, IT professional students, learning attitude, innovation and creativity, and then on the teaching quality and quantity, the curriculum system and curriculum evaluation.

\section{Operation Security}

Our country's pioneering education starts late, the operating mechanism is not mature, but the different social environment, the economic climate, the humanities background make our country enterprise education has the different growth and the development route with the overseas. But from the ten years of innovation and entrepreneurship education and practice exploration, the application oriented Undergraduate Colleges and universities IT professional innovation and entrepreneurship education in the operation of the need to operate in Colleges and universities, teachers and students, enterprises and government, and the operation of innovation and entrepreneurship education system has six important factors, as shown in Fig. 2.

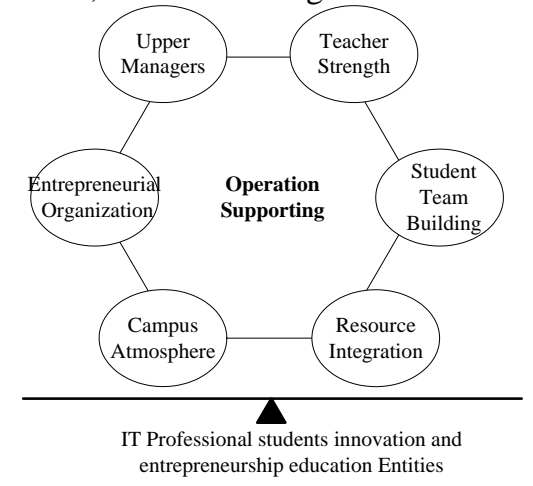

Figure 3. Practical Education Running Support

\section{IT PRACTICAL PLATFORM FOR INNOVATION AND ENTREPRENEURSHIP EDUCATION}

The ultimate goal of innovative and practical education in the application oriented Undergraduate Colleges and universities IT is to develop the practical ability of the students of this specialty. At present, the domestic colleges and universities have carried out a more in-depth exploration and practice in the construction of College Students' employment and entrepreneurship practice, creating a series of productive employment, entrepreneurial practice education and training mode, which can be divided into five stages, shown as Fig. 4 [1$2,6,9]$.

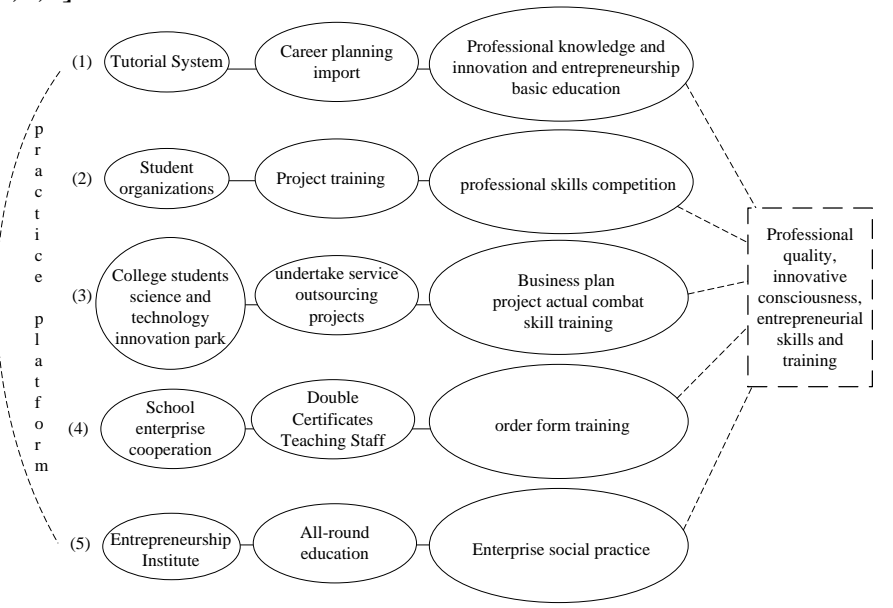

Figure 4. IT Professional Students Entrepreneurial Practice Platform

\section{A. Student Tutor System}

"Tutorial system" is not only the education of graduate students in Colleges and universities at present, but also a good policy for the newly introduced undergraduate colleges and universities. Through the qualification, selection and appointment, rewards and punishment, work process supervision and other strict procedures, select a number of outstanding teachers as students' tutor, leading them into the research project practice, to cultivate students' self-learning, independent thinking, professional innovation and teamwork ability. In the application oriented Undergraduate Colleges and universities, especially in IT, it is strongly advocated to carry out innovative teaching activities, and to develop students' innovative thinking, entrepreneurship and practical application ability, and to improve their professional theory level and project practice.

In a sense, the "tutorial system" is a kind of virtual business model, which is based on the project oriented, to improve students' practical ability and the use of learning model, mentor in the daily project development process to instill students' career planning, determine "what can you do? What would you do? And how to do it?" in their future life and career development. In the course of the students, the students carry out the project research. The whole process of the project needs analysis, overall design, detailed design and testing of the whole process of innovation and entrepreneurial skills to the students in the heart, in order to better realize the professional knowledge and innovation and entrepreneurship practice education to win, benefit maximization $[3,7]$.

\section{B. Student Associations and Studios}

Student studio can be the first time in the university campus to choose, so that students in the self-study and project training to get the improvement and knowledge of the deepening enrich the students' second classroom 
learning, to find their own strengths and interests. In the accumulation of knowledge progress and innovation, to encourage students to all types of business competition, it vendors organization skills contest, to participate in the business plan and other types of competitions, in order to better improve students' sense of competition, competition ability and the level of competition and the contest results enhance the students' sense of competition, team spirit. I shame the master spirit. The student community, especially IT professional studios and community, must follow the IT industry changes, in order to cultivate the IT professional students with a certain professional skills and innovation and entrepreneurship skills level as the main purpose, to give full play to students based on technology and ideas and ideas, students from the initial business incubation and technological innovation, infrastructure and other aspects of their own future ideas for the design, the students can use different learning strategies, from low to high, step by step, to promote the students' entrepreneurial activities.

\section{College Students' Science and Technology Innovation Park}

Incubator has a good innovation and entrepreneurship atmosphere, mature management guidance system, personal technology and market service mechanism, from the start of the training, entrepreneurship training, entrepreneurship simulation to the four stages of the enterprise to promote college students' entrepreneurship, not only can stimulate students' entrepreneurship, but can effectively improve the success rate of College students and entrepreneurial survival rate. Students can join the business park study and part-time, undertaking it outsourcing service project, establishing and improving the business plan, through a series of actual projects and skills training accumulated experience in research and development project, to build the school enterprise cooperation platform, it students entrepreneurial base, in order to pave the way for the further construction of the base of the steady progress. In addition, through the University's production and operation center business incubator, the use of rich in software and hardware resources, to help teachers and students to create a company, to provide business guidance, the introduction of innovation funds, to seek investment and technical investment, to promote student employment as a business, to truly realize the transition between entrepreneurship education and real business $[4-5,7]$.

\section{School Enterprise Cooperation, Production and Cooperation}

Entrepreneurship education is focused on the actual operation of the learning, school enterprise cooperation, production and cooperation practice platform, not only can let students contact with social practice place and the actual operation practice, for the school's reputation, resources, such as the opportunity to create more cooperation and promote the business education are helpful, and the industry can get more creative, innovative thinking direction, and contribute to its business. School enterprise cooperation to achieve win-win situation (such as our sun and rain Lenovo class), the school can take this a step further by promoting teaching reform, strengthen the double teacher team construction, students can also get more learning opportunities to practice, the enterprise can also better achieving the talent reserves. School enterprise cooperation management system and the "order form" training program, can make the students have the dual identity of prospective employees, to enhance the students' IT professional skills, entrepreneurship and innovation, and strive for a successful career in the IT, a new venture to achieve their dreams.

\section{E. Innovation and Entrepreneurship College}

In order to strengthen the students' innovation and entrepreneurship education, training innovative talents, conscientiously and an important measure to implement the province "entrepreneurial rich, strong innovation" total strategy, major colleges and universities to meet the national entrepreneurship education development trend, seize the national innovation strategy background in the economic, social and scientific research $[8,10]$, and other aspects of the development of the great opportunity, based on the social actual demand and the creation of the Institute of innovation and entrepreneurship. In the government, universities, enterprises and alumni, such as support, whether it is on the system or financial support and encouragement are helpful to promote innovation and entrepreneurship education and entrepreneurial environment, the goal is to develop innovative college has a sense of innovation.

\section{CONCLUSIONS}

In today's highly competitive industry, IT technology, IT technology, the background of the new era, combined with some engineering projects to innovative practice teaching activities, the professional teaching content and engineering practice, scientific and technological achievements. Through innovative practice teaching, students take the students tutor system and project driven teaching mode to guide students to participate in various competitions such as electronic design contest, college students "Challenge Cup" innovation and entrepreneurship competition, multimedia contest, program competition or lead students to participate in some engineering practice, so that students can experience the theory indispensable, practice is also essential, and then from the failure to sum up experience to achieve success, realize the real purpose of innovation. Through innovation and entrepreneurship education practice, pay attention to the cultivation of students learning process, make students in innovative practice and practice both theoretical learning and practice, the innovative practice throughout the university learning process, more conducive to innovation and entrepreneurship practice education and IT professional training program convergence, real training of a number of sets of knowledge, skills and emotional integration skills, application of IT talent, so that the University from the "knowledge creation", from "education" to "innovation and entrepreneurship education", so as to make the university become the cradle of innovation and entrepreneurship.

\section{ACKNOWLEDGEMENT}

The authors gratefully acknowledge the contributions of Fang Shouhu, Han Liru, Ma Yan, Lu Ke, Li Daqing, Tian Jinghua and Lu Saiqun for their work on the original version of this document. 
This work was supported by the project of 2015 Research on Educational Technology in Zhejiang Province (Project CODE: JB066) and Zhejiang Key Discipline of Instrument Science and technology.

\section{REFERENCE}

[1] Ou Yangxia, Wu Si. Reflections on the education modernization and the innovation and entrepreneurship education of graduate students [J]. Chinese Adult Education Journal, 2015 No.19: 68-69.

[2] Gu Hongjun, Gong He, Li Shijun. Exploration on the cultivation mode of talents under the background of College Students' innovation and Entrepreneurship Education [J]. Industry and Technology Forum. 2015 Vol14 No.20:159-160.

[3] Stowe R B. Entrepreneurship education in the United States [EB/OL] (2012-01-12 ) http://www.Docin.com/p- 387700687.html

[4] Mo Guangzheng, Ge Bing. Research on the construction and operation of the university entrepreneurship education system ([J].) 2013 (33): 74-80.

[5] Ning Zhong, Li Peiwen. Research on the three dimensional structure of the innovation and entrepreneurship education system
[J]. technology economics and management research, 2013 (01): 33-35

[6] Wang Qionghua, et al. Analysis of the composition and support of the American entrepreneurship education system and Its Enlightenment to China [J]. Vol.30 Journal of Chongqing Normal University (NATURAL SCIENCE EDITION), 2013 (01) No.1: 117-122.

[7] business should be the United States. The study on the protection of the practical education of College Students' employment and entrepreneurship education [J]. Journal of Changchun Normal University 2013 No.1: 114-117. Vol.32

[8] Chen Qiuying. The development of entrepreneurship education in Colleges and universities in Taiwan and the $[\mathrm{J}]$. innovation and entrepreneurship education, 2012 (12) Vol 3 100-103. No.6: 100103

[9] Chen Xi. Innovation and entrepreneurship education throughout the whole process of higher education in Colleges and universities [J]. China's higher education, 2010 (12): 4-6.

[10] $\mathrm{Du}$ Wei, the development of entrepreneurship education in Colleges and universities in China and Its Countermeasures [D], Nanjing University of Aeronautics \& Astronautics, 2010 (03) 